\title{
DIREITO À PROTEÇÃO DA SAÚDE PELA VIA JUDICIAL: EM BUSCA DE EFETIVIDADE E EQUIDADE
}

\author{
Marina Costa Ferreira*
}

SUMÁRIO: Introdução. 1. Judicialização da saúde: teoria e críticas atuais: 1.1. Origens e estágio atual do debate. 1.2. Contornos jurídicos do direito fundamental à proteção da saúde no Brasil. 2. A necessidade de concerto institucional. 2.1. Em busca de uma posição intermediária. 2.2. Em busca do diálogo institucional. 2.3. Efetividade e equidade: desafios e estratégias. Considerações finais. Referências.

RESUMO: Este artigo envolve a pesquisa das vias de materialização do direito fundamental à proteção da saúde orientada pela equidade. Tem sido muito tematizado o potencial discriminatório da intervenção judicial, ao argumento de que privilegia um grupo restrito que tem acionado o Poder Judiciário em busca de proteção, em detrimento do restante da população. Assume-se, por outro lado, que importantes falhas na regulação de saúde e os respectivos problemas de gestão, manifestados pelas deficiências na implementação de políticas existentes, exigem que os tribunais continuem a desempenhar um papel na efetivação do direito à proteção da saúde. Nesse sentido, pretende-se refletir sobre as vantagens do diálogo institucional que promove, ao lado da proteção de direitos sociais, a deliberação democrática, como uma alternativa ponderada favorável ao equilíbrio entre a efetividade das disposições constitucionais, o desempenho adequado da função judicial e o processo político majoritário em matéria de direitos sociais.

Palavras chave: Direito à saúde. Direitos fundamentais. Judicialização. efetividade. equidade.

ABSTRACT: The present article analyses ways of realizing the fundamental right to protection of health that are oriented by equity. The discriminatory potential of judicial intervention has been very thematized, in the sense that is favors a small group that has triggered the judiciary for protection, to the detrimento of the rest of the population. It is assumed, in the other hand, that major flaws in the regulation of health and management issues, manifested by deficiences in the implementation of existing policies, require that courts continue to play a role in ensuring the right to protection of health. Accordingly, qe intend to mediate on the advantages of institutional dialogue that promotes, along with the protection of social rights, democratic delieration, as an alternative weighted in favor of the balance between the effectiveness of constitutional provisions, the proper performance of judicial function and the political process in the area of social rights.

Keywords: Right to health. Fundamental rights. Judicialization. Effectiveness. Equity.

\section{INTRODUÇÃO}

Há situações e questionamentos que nos encontram para inquietar e acompanhar talvez durante toda uma vida. Durante discussão em sala de aula, deparei-me com a seguinte pergunta elaborada por colega e dirigida ao Professor: como o Direito pode ajudar a combater a grave desigualdade social que temos no Brasil? Na ocasião participei do debate apenas para observar que achava a pergunta por demais desafiadora e não conseguia sequer vislumbrar uma resposta, o que julgava lamentável. De toda sorte, tampouco me recordo de ter colhido alguma resposta satisfatória, embora todos concordassem com a perplexidade e importância da reflexão.

\footnotetext{
* Universidade de Brasília (UNB).
} 
Nesse mesmo sentido, é corriqueiro o descrédito em relação às disposições constitucionais que contemplam os direitos sociais (Constituição, art. $6^{\circ}$ ) em especial a saúde e a educação. São rotineiramente referidos como metas dirigidas aos governantes de melhoria da situação dos mais necessitados, enquanto bandeiras eleitoralmente atrativas no cenário político, mas de materialização insatisfatória. Em outras palavras, e mesmo fora do ambiente acadêmico, é comum falar-se em termos de promessas eleitorais descumpridas, e não propriamente em falha de proteção jurídica.

O direito à proteção da saúde tem atraído a atenção do ambiente acadêmico ao longo dos últimos anos justamente por estar, em princípio, deslocando o debate para a arena jurídica. $\mathrm{O}$ reconhecimento da aplicabilidade imediata do direito fundamental à proteção da saúde por meio de comandos judiciais que determinam ao Poder Público o fornecimento de prestações materiais tem sido problematizado como possível intervenção do Poder Judiciário na esfera de atribuições que competem aos demais Poderes relativas à condução de políticas públicas.

A Constituição expressamente refere a saúde como um direito de todos (Constituição, art. 196), que não pode convolar-se em "promessa constitucional inconseqüente"(RE 271286 AgR / RS, Rel. Min. Celso de Mello. Dj de 24.11.2000). O fato é que a realidade cotidiana revela as falhas na sua concretização e ao Judiciário é proposto o desafio de conferir eficácia a esse direito, observando os limites da atuação de cada Poder e critérios de justiça que se coadunem com a ordem de valores constitucionais.

É certo que não se trata de tarefa singela. A complexidade que envolve a interpretação do direito à proteção da saúde se deve à existência de múltiplos determinantes, bem como à co-titularidade dos direitos sociais no tocante à sua concretização: a esfera coletiva e difusa coexiste com a individual. Ademais, há inegáveis desdobramentos sobre a alocação de recursos, tema costumeiramente afeto à esfera política.

A produção acadêmica a respeito tem se concentrado em aspectos teóricos acerca da legitimidade do papel desempenhado pelas cortes em um contexto democrático e em discussões abstratas sobre sua capacidade institucional. Em um plano pragmático, as principais críticas se voltam aos efeitos dessas decisões sobre a gestão administrativa, sobretudo no que se refere à condução estável e sustentável de políticas públicas.

O problema que se pretende investigar nesse quadro se volta à seguinte indagação: é possível afirmar que a judicialização da saúde nos moldes do Estado brasileiro tem a aptidão de contribuir para o aperfeiçoamento do sistema orientado pela equidade? Nesse contexto, cumpre ressaltar que a própria Constituição elege a justiça social como objetivo da ordem social (Constituição, art. 193). Assim, a investigação se afina ao escopo constitucional de toda a ordenação jurídica relativa à seguridade social.

Por certo, o apanágio teórico merece detida análise porque permite uma crítica balizada da realidade consolidada. Não obstante, o corte epistemológico da 
presente pesquisa privilegia o viés pragmático do problema. Busca-se averiguar o desenho institucional que se revele favorável à materialização especificamente do direito à proteção da saúde, com ênfase no papel a ser desempenhado pelo Poder Judiciário.

Muitos autores têm abordado o potencial discriminatório ou antiisonômico da intervenção judicial, ao argumento de que privilegia um grupo restrito que tem acionado o Poder Judiciário em busca de proteção, em detrimento do restante da população. O presente artigo pretende demonstrar a eficácia da inserção de mecanismos de diálogo institucional para reorientar os resultados da atuação judicial à materialização equânime do direito à proteção da saúde.

A expectativa é de que se reconheça, ao mesmo tempo, o pleno potencial e os limites institucionais dos três poderes - num contexto de generalizada e razoável discórdia sobre o conteúdo e a prioridade a ser dada aos compromissos constitucionais - e a urgente necessidade de realizar esses compromissos. Como a ênfase é a atuação dos magistrados, buscam-se formas de revisão judicial ativas e reflexivas que ajudem a aumentar a abrangência e a capacidade de resposta dos processos globais de deliberação, por ser essa a via para concretização do direito à proteção da saúde orientada pela equidade.

Para aplicar as premissas teóricas ao contexto brasileiro, é necessária uma avaliação concreta do perfil dos litígios em saúde. Procurou-se verificar se as complexidades suscitadas em abstrato pela literatura especializada têm conduzido a problemas reais, bem como se e em que medida é possível amoldar as propostas de diálogo institucional à realidade brasileira.

\section{JUDICIALIZAÇÃO DA SAÚDE: TEORIA E CRÍTICA ATUAIS}

\subsection{Origens e estágio atual do debate}

Nos últimos anos tem sido observado um aumento do volume de litígios envolvendo direitos sociais. Muitos autores $\mathrm{o}$ associam à sua constitucionalização, particularmente na América Latina, Leste Europeu e África (BARROSO, 2007, p. 34-35; STRECK, 2011, p. 3). Outros sustentam que o fenômeno resulta da configuração da sociedade civil, no sentido de que a maioria dos novos precedentes em matéria de concretização de direitos sociais decorre da atuação concertada de movimentos sociais e organizações de direitos humanos (LANGFORD, 2009, p. 102).

Segundo atesta o Professor Luiz Roberto Barroso, o fenômeno da judicialização das relações sociais no Brasil desenvolveu-se no contexto de constitucionalização - na esteira da corrente neoconstitucionalista - associado ao aumento da demanda por justiça e à ascensão institucional do Judiciário (BARROSO, 2007, p. 34-35). Não há uma conceituação precisa do conteúdo da 
linha neoconstitucionalista que reúne juristas de diversas posições jusfilosóficas e de filosofia política, mas se pode delinear alguns denominadores comuns ${ }^{1}$ :

a) a importância dada aos princípios e valores como componentes elementares dos sistemas jurídicos constitucionalizados; b) a ponderação como método de interpretação/aplicação dos princípios e de resolução dos conflitos entre valores e bens constitucionais; c) a compreensão da Constituição como norma que irradia efeitos por todo o ordenamento jurídico, condicionando toda a atividade jurídica e política dos poderes do Estado e até mesmo dos particulares em suas relações privadas; d) o protagonismo dos juízes em relação ao legislador na tarefa de interpretar a Constituição; e) enfim, a aceitação de alguma conexão entre Direito e moral. (VALE, 2007, p. 67)

A despeito de todo o risco de excessiva ênfase na atuação do Poder Judiciário, encontro nesse paradigma um reforço às expectativas de conferir efetividade aos comandos constitucionais, em especial, os direitos sociais. Nas palavras de Daniel Sarmento (2009, p.3), "o neoconstitucionalismo alenta um ideário humanista, que aposta na possibilidade de emancipação humana pela via jurídica, através de um uso engajado da moderna dogmática constitucional". Nesse contexto, a decisão acerca do papel constitucionalmente adequado a ser desempenhado pelo Poder Judiciário aproxima a argumentação jurídica a questões de Filosofia Política, envolvendo importantes debates entre procedimentalistas e substancialistas.

A primeira corrente, representada por autores como Jürgen Habermas e Antoine Garapon, entende que o incremento do controle judicial prejudica o exercício da cidadania ativa, uma vez que envolveria uma postura paternalista. Assim, o Poder Judiciário deveria apenas garantir procedimentos para ampla deliberação democrática. A segunda corrente, adotada por Mauro Cappelletti e Ronald Dworkin, é a dos chamados substancialistas, que entendem que o Judiciário é o intérprete do justo na prática social: deve assegurar que as políticas públicas garantam a democracia e os direitos fundamentais e não interesses hegemônicos específicos (SANTOS, 2003, p. 271-272). Segundo Daniel Sarmento (2009, p. 4) o neoconstitucionalismo se identifica mais com a corrente substancialista, que ressalta o papel do Judiciário em favor dos valores constitucionais.

O fato é que as decisões judiciais em matéria de saúde tiveram um crescimento vertiginoso nos últimos anos, atraindo as atenções para os riscos de um alegado ativismo judicial. Elas eram pouco significativas, na década anterior, mas um levantamento que vem sendo realizado pelo Conselho Nacional de

${ }^{1}$ Segundo André Rufino do Vale (2007, p. 67), "o termo neoconstitucionalismo pode ser utilizado como fazendo referência a uma teoria, a uma ideologia ou a um método de análise do direito; ou como designando alguns elementos estruturais de um sistema jurídico e político, um modelo de Estado de Direito. Sobre as diversas acepções do termo neoconstitucionalismo, vide: COMANDUCCI, Paolo. Formas de (neo)constitucionalismo: un análisis metateórico. In: CARBONELL, Miguel (ed.). Neoconstitucionalismo(s). Madrid: Trotta; 2003, p. 75". 
Justiça (CNJ) constatou que hoje tramitam mais de 112 mil ações desse tipo em 20 dos 91 tribunais brasileiros. Os técnicos do CNJ estimam que, quando concluírem o exame dos dados dos 71 tribunais que ainda não foram pesquisados, o número de ações judiciais relativas a questões de saúde ficará em torno de 500 mil $^{2}$. No próximo tópico, examina-se como tem sido a leitura dos doutrinadores e da jurisprudência dos contornos jurídicos do direito à proteção da saúde inserido no paradigma do Estado Social Brasileiro.

\subsection{Contornos jurídicos do direito fundamental à proteção da saúde no Brasil}

A inclusão do art. 196 - que contempla o direito à proteção da saúde - na Constituição foi uma conquista do movimento sanitarista que desde a década de 1970 lutava pelo acesso universal aos serviços e ações em saúde, pela descentralização de seu funcionamento e administração e pela mudança de uma perspectiva curativa para a preventiva (FERRAZ, 2010, p. 33).

A estrutura do direito fundamental à proteção da saúde envolve uma dupla dimensão de direitos subjetivos individuais e elementos objetivos fundamentais. Nesse sentido, envolve decisões valorativas de natureza jurídicoobjetiva, com eficácia sobre todo o ordenamento, e que fornecem diretrizes para os órgãos dos Poderes Legislativo, Executivo e Judiciário. Além disso, num plano subjetivo, o titular pode fazer valer judicialmente os poderes, as liberdades ou o direito à ação ou às ações negativas ou positivas que lhe são inerentes (SARLET, 2007, p. 166-180).

Enquanto direito fundamental, envolve uma proibição de intervenção (Eingriffsverbote), bem como um postulado de proteção (Schutzgebote). Haveria, portanto, não apenas uma proibição de excesso (Übermassverbot), mas também uma proibição de proteção insuficiente (Untermassverbot) (MENDES; BRANCO, 2011, p. 667).

Segundo uma dimensão objetiva, sobressai ainda a perspectiva dos direitos à organização e ao procedimento (Recht auf Organization und auf Verfahren), os quais dependem, na sua concretização, de providências estatais com vistas à criação e à conformação de órgãos e procedimentos indispensáveis à sua efetivação. (MENDES;BRANCO, 2011, p. 677). No caso da saúde, temos o exemplo das disposições do art. 200 da Constituição acerca das atribuições do Sistema Único de Saúde: ações de vigilância sanitária e epidemiológica e de saúde do trabalhador (inciso II); ações de saneamento básico (IV); pesquisa (V); controle de qualidade de alimentos e bebidas (VI) e proteção do meio ambiente (VIII).

${ }^{2}$ CAVAlCANTI, Hylda. Demandas de saúde passam de 112 mil em todo o país. Agência CNJ de Notícias. Disponível em: https://www.cnj.jus.br/noticias/10118-demandas-de-saude-passam-de-112mil-em-todo-o-pais. Acesso em 10.03.2011. 
Ainda que para alguns soe trivial a afirmação de que seria o direito à proteção da saúde um direito fundamental de aplicabilidade imediata (MENDES; BRANCO, 2011, p. 670-680; SARLET, 2007, p. 1-3; PIOVESAN, 2008. p. 163), cabe referir a existência de doutrina em sentido diverso. Argumenta-se que os direitos sociais não derivam da simples natureza humana do indivíduo - nota característica dos direitos fundamentais -, mas decorreriam do pertencimento a determinado grupo ou categoria, ou ainda de eventual posição nas relações sociais (TAVEIRA; TRAVASSOS, 2009, s.p.).

Os defensores dessa última corrente, de toda sorte, não afastam a sua justiciabilidade: sustentam, sim, que a atribuição excessiva de conteúdo a ditos direitos retiraria matérias do âmbito de deliberação política democrática. Não obstante, em determinada parcelas mínimas, suas prestações podem ser imprescindíveis à realização dos direitos humanos, sofrendo uma "transubstanciação" para a natureza jusfundamental apta a gerar direitos subjetivos aos respectivos titulares.

Em outras palavras, trata-se de considerar os direitos sociais diretrizes políticas (policies), segundo a doutrina de Dworkin: políticas passíveis de serem adotadas pela sociedade para o bem comum, salvo quando tocadas em um mínimo que estabeleça condições de liberdade (TAVEIRA; TRAVASSOS, 2009, s.p.). Nesse sentido, sustenta Ricardo Lobo Torres (2003, p. 1-2):

\begin{abstract}
A jusfundamentalidade dos direitos sociais se reduz ao mínimo existencial, em seu duplo aspecto de proteção negativa contra a incidência de tributos sobre os direitos sociais mínimos de todas as pessoas e de proteção positiva consubstanciada na entrega de prestações estatais materiais em favor dos pobres. Os direitos sociais máximos devem ser obtidos na via do exercício da cidadania reivindicatória e da prática orçamentária, a partir do processo democrático.
\end{abstract}

Assentada essa distinção, constata-se a importância de definir o que seriam essas parcelas mínimas, referidas como mínimo existencial pela doutrina, por certo um dos temas mais tormentosos dentro da hermenêutica de direitos fundamentais. O desafio se agiganta quando aliado ao problema da escassez de recursos, a denominada reserva do possível.

A interpretação do conteúdo do mínimo existencial que tem prevalecido na doutrina e jurisprudência constitucional comparada é a de um conjunto de garantias materiais para uma vida condigna, que limita a liberdade de conformação do legislador (SARLET; FIGUEIREDO, 2008, p. 192-194). Não obstante, é inviável fixar, num plano abstrato, um elenco de prestações aptas a satisfazer o mínimo existencial a ser assegurado pelo Estado, pois tal constatação demanda a análise das peculiaridades do destinatário do benefício em concreto (SARLET, 2007, p. 300). Nesse sentido, por exemplo, tem-se sustentado a necessidade de comprovação da hipossuficiência do requerente de uma determinada prestação de saúde. No Rio Grande do Sul, a Lei n. 9.908/93 já prevê 
a comprovação prévia da carência de recursos como pressuposto à prestação estatal de medicamentos excepcionais.

Associada à defesa de reservas quanto às prestações materiais que devem ser proporcionadas pelo Estado, através da restrição àquelas inseridas em um núcleo mínimo assegurador de uma vida condigna, está a alegação de limitação dos recursos públicos. Não se pode considerar o argumento de escassez uma falácia, mas o certo é que o ônus de comprovar a falta efetiva dos recursos é do Poder Público, que não o tem feito a contento, limitando-se a referir em um plano absolutamente abstrato a "reserva do possivel".

Em verdade, a escassez de recursos, apontada como o principal limite fático à efetivação do direito à proteção da saúde, contempla duas perspectivas. A primeira envolve a constatação de que os recursos públicos se destinam à proteção de diversos interesses, dos quais a saúde é apenas exemplo, falando-se, nesse caso, em escassez relativa ${ }^{3}$. A partir do momento em que se destina determinada porção do orçamento à área da saúde, passa-se a investigar como os recursos devem ser alocados para atender às diversas necessidades da população (escassez absoluta) (FERRAZ; VIEIRA, 2009).

O certo é que, em ambos os casos, há a necessidade de eleição de critérios para alocar os escassos recursos, com fundamento em princípios de justiça distributiva, que privilegiem a promoção de justiça social. No caso do direito à proteção da saúde, enquanto direito social, fala-se em um propósito compensatório no sentido de garantir a participação do povo na distribuição pública de bens, nota distintiva do paradigma do Estado Social (SARLET, 2007, p. 299).

Registre-se que a resistência doutrinária e mesmo jurisprudencial ao controle direto dos orçamentos pelo Judiciário oculta a realidade de que o expediente de implementação de direitos prestacionais acarreta impactos que, de toda sorte, obrigam à reorientação dos cronogramas financeiros (TAVEIRA; TRAVASSOS, 2009, s.p.). Assim, o Poder Judiciário acabou por se transformar em instrumento de pressão orçamentária ao consolidar a eficácia imediata do direito à proteção da saúde, ensejando a nova conformação de prioridades dentro da elaboração política legislativa.

Ferraz (2010, p. 41) faz interessante comparação que ilustra o problema: em 2008, o Estado de São Paulo gastou aproximadamente 400 milhões de reais para cumprir mandados judiciais que beneficiaram cerca de 35.000 pessoas. Segundo notícia veiculada pelo sítio da Fiocruz, o Ministério da Saúde anunciou um gasto de igual monta para aquisição de 13 milhões de doses da vacina pneumocócica para aplicação em crianças menores de 2 anos de idade, num total aproximado de 6 milhões de crianças. A partir de 2011, elas farão parte do calendário básico de vacinação da criança, específico para os menores de 1 ano. Depois de cinco anos do início dos novos programas de vacinação, portanto em

${ }^{3}$ Quanto à escassez relativa, é importante referir a edição da Emenda Constitucional n. 29/2000 que assegura os recursos mínimos para o financiamento das ações e serviços públicos de saúde, mas que ainda carece de regulamentação. 
2015, a previsão é de que a média dessas internações por ano cairá de 54.427 para 9.185, uma redução de $83 \%{ }^{4}$.

O exemplo evidencia como o mesmo montante de recursos públicos pode ter impactos absolutamente distintos. A estratégia de ação preventiva, que segundo a Constituição deve ser priorizada ( $\operatorname{art.} 198, \mathrm{II}^{5}$ ), tem a potencialidade de alcançar grande número de beneficiários, indistintamente, com redução a longo prazo da incidência da patologias, cujos benefícios são inúmeros, dentre os quais, a diminuição do gasto com procedimentos curativos. Os mandados judiciais, por seu lado, garantem, de plano, a eficácia do direito à proteção da saúde em relação a indivíduos determinados.

Além de positivar o direito à proteção da saúde, a Constituição estabelece todo um plexo de princípios regedores das políticas públicas de saúde. O primeiro deles é a universalidade da cobertura e do atendimento: todos têm direito à proteção da saúde, sendo dever do Estado a garantia do acesso (art. 194, I c/c art. 196, caput).

O Sistema Único de Saúde tem como diretrizes, em síntese apertada, a descentralização, a participação da comunidade através dos Conselhos de Saúde e o atendimento integral (art. 198). Em relação aos princípios diretivos elencados pela Constituição, certamente a integralidade atrai as maiores controvérsias (art. 198, II), uma vez que é utilizada por muitos como argumento para a entrega de todo medicamento ou tratamento que se façam necessários. Outros salientam que se trata de uma "integralidade regulada": deve estar dependente da obrigação do Estado de regular o sistema, em conjunto com a população, por meio dos conselhos de saúde, pois seria impossível e irracional se pensar que a integralidade seja um conceito aberto (NARDI, 2009).

O certo é que o gestor deve buscar diminuir a variação na prática clínica, garantir boas práticas na assistência e melhorar os resultados esperados. Assim, são editados instrumentos de gestão como Protocolos Clínicos de Diretrizes Terapêuticas $\left(\mathrm{PCDT}^{6}\right)$ e as listas oficiais de dispensação ${ }^{7}$.Tais documentos não podem ser encarados como expedientes para economizar ou reduzir gastos, mas sim de utilização dos recursos de maneira racional, de maneira a ampliar a

\footnotetext{
${ }^{4}$ SUS oferece duas novas vacinas para 6 milhões de crianças. Fiocruz Minas - Centro de Pesquisas René Rachou. Disponível em: http://www.cpqrr.fiocruz.br/pt-br/noticias-gerais/sus-oferece-duas-novasvacinas-para-6-milhoes-de-criancas. Acesso em 10.03.2011.

${ }^{5}$ Art. 198. As ações e serviços públicos de saúde integram uma rede regionalizada e hierarquizada e constituem um sistema único, organizado de acordo com as seguintes diretrizes:(...)

II - atendimento integral, com prioridade para as atividades preventivas, sem prejuízo dos serviços assistenciais;

${ }^{6}$ Os PCDT são recomendações, desenvolvidas por meio de revisão sistemática da literatura existente, para dar suporte à decisão do profissional e do paciente acerca do tratamento mais apropriado, no que se refere às condutas preventivas, diagnósticas ou terapêuticas dirigidas para determinado agravo em saúde ou situação clínica (CONASS, 2007, p. 121).

${ }^{7}$ Essas listas indicam os medicamentos que serão fornecidos pelo Poder Público considerando as melhores evidências disponíveis e morbidades prevalentes, eficácia, efetividade, segurança e qualidade do fármaco, apresentações farmacêuticas que atendam as necessidades, comodidade posológica, custo e disponibilidade no mercado.
} 
cobertura e variedade dos medicamentos (BARATA; MENDES, 2010, p. 71). Sobressai uma nova especialidade ou área de conhecimento, a economia da saúde:

Economia da saúde pode ser definida como o estudo de como os indivíduos e sociedades exercem a opção de escolha na alocação dos escassos recursos destinados à área da saúde entre as alternativas que competem para seu uso e como esses escassos recursos são distribuídos entre os membros da sociedade. Essa definição abrange, na sua primeira parte, a questão da eficiência do sistema de saúde, ou seja, como produzir mais saúde para um todo (...) A segunda parte dessa definição aborda a questão da equidade. Ou seja, esse conjunto de serviços e produtos deve atender às expectativas de diferentes grupos de indivíduos da forma mais harmônica possível, sem privilegiar um grupo em detrimento do outro (BOSI FERRAZ, 2010, p. 129).

A discussão acerca dos medicamentos e tratamentos que devem ser contemplados, notadamente, envolve políticos, técnicos administrativos, indivíduos e a opinião pública, os quais, respectivamente, privilegiam princípios alocativos diversos: eficiência global, eficiência local, interesse individual e justiça social. Assim, um modelo alocativo satisfatório deve conciliar os diversos atores e seus respectivos interesses (ELSTER, 2000).

Nesse contexto, o recurso à via judicial para o fornecimento de medicamentos e tratamentos padronizados não tem ensejado maiores indagações; a perplexidade se volta às ordens ao Poder Público para que entregue medicamentos que não constam das listas oficiais ou providencie tratamentos não contemplados pelas diretrizes clínicas publicadas. Nesses casos, o Judiciário brasileiro não tem conferido deferência ao processo de deliberação, que envolve diversos interesses e princípios alocativos, destinado a tornar racional a utilização dos escassos recursos. O problema é agravado diante da realidade de que predominam nessa seara a concessão de tutelas de urgência (liminares, segurança ou tutelas antecipadas) sem a prévia oitava do gestor, que deve acatar a ordem judicial e, simultaneamente, sustentar a demanda ordinária do sistema (PEPE et al, 2010, p. 2406).

Há forte doutrina norte-americana que salienta a incapacidade dos tribunais de lidar com essas questões que têm impactos de natureza distributiva, linha esta adotada por autores como Rosenberg, Sunstein e Fuller, a cujas teorias são feitas referências ao longo da presente pesquisa. Rosenberg (1991), por exemplo, elenca algumas razões para o seu descrédito: conflitos distributivos demandam reformas sociais e não simples adjudicação; os tribunais não dispõem de meios institucionais para implementar e monitorar decisões que implicam alguma programa continuado ou política pública; o princípio da inércia coloca o Judiciário em uma posição passiva que inviabiliza a adoção de uma agenda de reforma.

Os clássicos argumentos contrários à atuação do Poder Judiciário nessa seara se voltam à potencial violação ao princípio da separação de poderes e à ausência de legitimidade democrática, uma vez que juízes não são eleitos e, 
portanto, devem observar as deliberações do espaço político, sobretudo no que se refere à seleção de prioridades.

Além disso, a exigência de conhecimentos técnicos estranhos ao Direito recomendariam uma postura de autocontenção, pois o Judiciário careceria de capacidade institucional para lidar com problemas socioeconômicos altamente complexos. Nesse sentido, Lon Fuller (1979, p. 394-410) refere o dilema policêntrico, segundo o qual o magistrado não deve ocupar-se de assuntos que tenham repercussões drásticas para além das partes e dos fatos trazidos à cognição do tribunal.

Nessa linha, destaca-se o fato de que um tribunal não possui recursos para lidar com problemas intricados dessa jaez: limitações de ordem procedimental, o número reduzido de litigantes e, em geral, as poucas informações não permitem compreender a complexidade de planejamento e implementação de políticas públicas (INTERNATIONAL COMISSION OF JURISTS, 2008, p. 92). Ademais, há dificuldades práticas do cotidiano do Judiciário como a excessiva carga de trabalho, ou a deficiente formação jurídica (SARMENTO, 2009, p.6).

Outro problema constantemente referido seria o esfriamento de outros setores da sociedade em termos de mobilização cívica. As pessoas confiam ao controle judicial tarefas cujo desempenho seria potencialmente mais satisfatório se realizado por cidadãos comuns comprometidos com os valores constitucionais. Nesse ponto, Daniel Sarmento apresenta sua crítica mais acentuada ao que chama de obsessão com a interpretação judicial que afastaria o papel de outros intérpretes como os membros do Poder legislativo, do executivo e a própria esfera pública informal:

\footnotetext{
Trata-se de um desvio que gera consequências negativas tanto no plano descritivo como na esfera normativa. Sob o prisma descritivo, transmite-se uma imagem muito parcial do fenômeno constitucional, que não é captado em todas as suas nuances e riquezas, já que o foco se concentra apenas sobre a ação de um dentre os vários agentes importantes que povoam a seara da hermenêutica constitucional. Sob o ângulo normativo, favorece-se um governo à moda platônica, de sábios de toga, que são convidados a assumir uma postura partenalista diante de uma sociedade infantilizada (2009, p. 6).
}

Segundo Sarmento (2009, p.6), no Brasil, é comum vincular-se o ativismo judicial a posições progressistas. Para ele, trata-se de falso paralelismo, pois o Judiciário pode atuar em defesa do status quo, utilizando-se, inclusive, da retórica dos direitos fundamentais.

Os defensores de um papel ativo do Poder Judiciário, por outro lado, argumentam que a própria teoria democrática reúne premissas que permitem sustentá-lo. A ideia de democracia não se resumiria ao principio majoritário: o processo político majoritário pode se mover por interesses, enquanto a lógica democrática se inspira em valores (BARROSO, 2007, p. 38). 
Nesse sentido, o Professor Roberto Gargarella (2006, p 14-29) tem defendido uma concepção deliberativa de democracia. Para ele, um compromisso com a democracia não implica privar o Judiciário de atuar na proteção aos direitos sociais, pois tal postura derivaria de algumas teorias específicas, como a teoria pluralista, ou de leituras questionáveis acerca dos objetivos democráticos.

A concepção deliberativa de democracia requer que as decisões públicas sejam tomadas após um amplo processo de discussão coletiva, do qual participem todas as pessoas potencialmente afetadas pela decisão:

\begin{abstract}
A noção inclui uma decisão coletiva com a participação de todos os que serão afetados pela decisão ou os seus representantes: esta é a parte democrática. Além disso, todos concordam que inclui a tomada de decisões por meio de argumentos oferecidos pelos e para os participantes que estão comprometidos com os valores da racionalidade e da imparcialidade: esta é a parte deliberativa (ELSTER apud GARGARELLA, 2006, p. 34)
\end{abstract}

A partir dessas assertivas, Gargarella defende que tal concepção de democracia rejeita a supremacia judicial, uma vez que todas as questões devem estar abertas à discussão em curso entre todas as partes afetadas. Por outro lado, há espaço para que os juízes recebam as reclamações de todos aqueles que se sintam preteridos pelas decisões das instituições políticas. Num plano institucional, o judiciário representaria o principal canal para que os grupos marginalizados possam se fazer ouvir. Assim, "juizes poderiam contribuir decisivamente para 'ativar' $e$ enriquecer as discussões, de maneira a favorecer à elaboração de decisões públicas mais imparciais" (GARGARELLA, 2006, p. 28).

Nesse contexto, ressalta-se a função do Judiciário de demandar prestação de contas dos outros poderes e não de formular políticas, bem como a sua capacidade de servir como fórum para que as pessoas interajam com o Estado no que tange aos seus direitos fundamentais de forma mais ponderada (LANGFORD, 2009, p. 107).

A objeção de caráter institucional, referente à ausência de conhecimentos sobre questões econômicas e sociais relevantes, pode ser relativizada. São problemas contornáveis a partir do auxílio de órgãos ou assistências especializados, como núcleos de assessoria técnica.

Quanto ao dilema policêntrico, por certo é um dos problemas mais desafiadores. Uma visão mais abrangente do quadro político, social e econômico refoge ao alcance do magistrado vocacionado à cognição parcial. Segundo Langford (2009, p. 108), essa objeção não tem afetado a atuação dos tribunais, mas impulsionado inovações judiciais, como o uso de princípios jurídicos claramente definidos a exemplo da razoabilidade, ou ainda a adaptação de procedimentos e de remédios judiciais.

Em um plano pragmático, verificam-se ainda dificuldades para forçar o adimplemento das decisões quando demandam alterações estruturais. Como consequência da apontada debilidade para concretizar os seus comandos, sobressai uma das críticas mais sólidas à atuação do Poder Judiciário: a 
impossibilidade de satisfazer à expectativa de alcançar a justiça social transformadora (LANGFORD, 2009, p. 117).

Do exposto extrai-se que as indagações oferecidas relacionadas ao problema judicialização desafiam uma solução intermediária entre as posições radicais que negam completamente a ação do Poder Judiciário e as que pregam a existência de um direito subjetivo a toda e qualquer prestação de saúde. Pretende-se demonstrar que não existem apenas duas opções radicais: a colonização total da política pelo direito ou a absoluta ausência de controle jurídico em matéria de políticas públicas (BARCELLOS, 2008, p. 158).

\section{A NECESSIDADE DE CONCERTO INSTITUCIONAL}

\subsection{Em busca de uma posição intermediária}

A abordagem doutrinária, como demonstrado, tem se centrado em elementos da teoria democrática para tolher a atuação das cortes. As grandes questões, não obstante, seriam (i) onde traçar tais limitações e (ii) se inovações jurisprudenciais, procedimentais ou em relação aos remédios judiciais podem resolver essas indagações (LANGFORD, 2009, p. 102).

Em uma versão mais limitada da crítica, Cass Sunstein defende que a indagação se volta à amplitude da função judicial (SUNSTEIN apud TUSHNET, 2009 , p. 233). Pretende-se estudar um modelo institucional que favoreça o equilíbrio entre a efetividade das disposições constitucionais, o desempenho adequado da função judicial e o processo político majoritário em matéria de direitos sociais.

Literatura crescente em direito constitucional comparado tem se dedicado à construção de modelos teóricos que promovam, ao lado da proteção de direitos sociais, a deliberação democrática. Essa posição intermediária entre a contenção judicial e a juristocracia (juristocracy) tem sido denominada ativismo dialógico (dialogic activism): não obstante defendam a justiciabilidade de tais direitos, criticam decisões que, ao impor o cumprimento detalhado de políticas e programas, adentram o espaço destinado à deliberação democrática ocupado tradicionalmente pelos Poderes Executivo e Legislativo.

\section{2 . Em busca do diálogo institucional}

Inicialmente, é importante asseverar que as que as teorias aqui expostas se aplicam ao tema de implementação de direitos sociais e não se confundem com as propostas do diálogo institucional na seara do controle de constitucionalidade, apesar de ambas se voltarem ao enfrentamento da objeção fundada na ausência de legitimidade do ponto de vista democrático, em atenção à separação dos poderes. 
A pesquisa da literatura e dos discursos proferidos na Audiência Pública Saúde no Supremo Tribunal Federal ${ }^{8}$ permitiu a constatação de que o desafio de implementação do direito à proteção da saúde orientado pela equidade tem levado a uma ênfase na necessidade de diálogo, referindo-se: um "diálogo institucional responsável" (SARLET, 2009), a necessidade de "fomento de espaços institucionais formais de diálogo" (PEPE et al, 2010, p. 2412), uma "solução compartilhada" (VIEIRA; ZUCCHI, 2007), a "promoção da inter-relação" (SOUZA;SANTOS;UETA, 2010, p. 171); "espaços de consenso"(OLIVEIRA, 2009); "um tipo de concertação" (MENDES; BRANCO, 2011, p. 713); "alguma interação entre o judiciário e as instituições políticas"(INTERNATIONAL COMISSION OF JURISTS, 2008, p. 84).

Conforme ressaltado por Sarmento (2009, p.1), tem havido acentuada produção acadêmica no cenário anglo-saxão sobre modelos teóricos que favoreçam o diálogo entre órgãos e instituições acerca da implementação de direitos sociais. Nesse contexto, preciosas são as lições da Professora Rosalind Dixon (2006), sobre as vantagens das decisões co-participadas.

Os defensores do diálogo institucional argumentam que, mesmo nas democracias mais desenvolvidas, os processos políticos majoritários são muitas vezes sujeitos a dois graves problemas: os pontos cegos ("blind-spots") e os encargos da inércia ("burdens of inertia"). Neste contexto, formas de revisão judicial ativas e reflexivas terão uma importante capacidade de ajudar a aumentar a abrangência e a capacidade de resposta dos processos globais de deliberação constitucional. Assim, os resultados obtidos em sistemas em que o Judiciário adota uma postura de pura auto-contenção ficariam totalmente aquém do ideal constitucional (DIXON, 2006, p. 22).

Os pontos cegos que sobressaem no processo deliberativo democrático indicam falhas na regulamentação concretizadora de direitos ("blind-spots of application"), na apreciação do impacto das escolhas efetuadas ("blind-spots of perspective"), e na acomodação de interesses e prioridades ("blind-spots of accommodation").

Quanto aos encargos da inércia ("burdens of inertia"), Dixon (2006, p.23) também refere três problemas: temas podem deixar de ser tratados por causa de outras prioridades que sejam imediatamente e eleitoralmente mais relevantes ("priority-driven burdens of inertia"); os encargos de inércia também podem surgir em face de uma questão que divida a coesão interna do partido no comando, de maneira que a realização de um projeto gere elevados os custos para a coerência e a integridade do partido ("coalition-driven burdens of inertia"); e, finalmente, quando a concretização de um direito exige complexas formas de ação administrativa, há um verdadeiro potencial para produzir "encargos burocráticos da inércia ("bureaucratic burdens of inertia"): a realização é

\footnotetext{
${ }^{8}$ Os discursos proferidos na Audiência Pública Saúde estão disponíveis na página do Supremo Tribunal Federal: $\quad$ http://www.stf.jus.br/portal/cms/verTexto.asp?servico=processoAudienciaPublicaSaude. Acesso em 10.12.2010.
} 
dificultada por uma combinação de atrasos administrativos e falta de fiscalização legislativa.

A teoria do diálogo não propõe que os tribunais devam intervir no processo político somente no caso de erro evidente ou patente irracionalidade por parte do legislador ou do executivo à luz dos entendimentos comuns quanto ao alcance e prioridade a ser dada a particulares direitos. Os tribunais têm, sim, o direito de intervir, quer coercivamente, quer comunicativamente - ou, no caso do diálogo, eventualmente em ambos os sentidos -, em circunstâncias onde há falhas discutíveis de previsão, de perspectiva, de acomodação de interesses, ou de resposta (DIXON, 2006, p. 29).

Nesse contexto, recomenda-se uma abordagem cautelosa por parte do Judiciário por meio de comandos comandos cujo conteúdo seja mais brando 9 (DIXON, 2006, p. 39-40). A abordagem dialógica estimula, ainda, a participação da comunidade, por exemplo, por meio de audiências públicas, que aprofundam a deliberação democrática e tendem a melhorar o impacto das decisões (GARAVITO, 2011, p.8). Além disso, os mecanismos de diálogo auxiliam a superação dos problemas dos magistrados com o conhecimento técnico para encontrar e implementar soluções. Isso porque essas devem ser elaboradas com alguma ingerência dos diversos setores envolvidos - autoridades públicas, líderes e membros da população beneficiada, especialistas de universidades, organizações da sociedade civil. Efeitos diretos e indiretos desse diálogo incluem o desbloqueio de processos políticos, a coordenação entre diferentes órgãos estatais e a criação de políticas públicas moldadas segundo uma linguagem de direitos.

É preciso ressaltar, porém, ainda num plano teórico, que há um componente dinâmico: se o remédio fraco é ineficaz, deve ser substituído por um mais intenso. Se, ainda assim, o problema não for resolvido, buscam-se novas

${ }^{9}$ Colhem-se no direito comparado exemplos de remédios judiciais brandos que privilegiam o diálogo (LANGFORD, 2009, p. 116):

(i) o maior uso de uma declaração retardatária de invalidez de um ato jurídico, por meio da qual os tribunais determinam que ocorreu uma violação, mas retardam o efeito da decisão para dar ao governo tempo para encontrar a melhor forma de reparar o defeito existente na legislação ou na política em questão (CANADÁ, Eldridge vs. British Columbia, 1997);

(ii) o maior uso que fazem os tribunais (e, muitas vezes, organismos internacionais) do processo judicial como espaço de diálogo com as partes, o que incluiu instigar que estas encontrem soluções antes que uma decisão final seja tomada (ÁFRICA DO SUL, Occupiers of 51 Olivia Road, Berea Township And Or. vs. City of Johannesburg and Others, 2008);

(iii) a elaboração de recomendações. Os tribunais da Índia e de Bangladesh, por vezes, têm adotado este enfoque no lugar de emitir ordens finais ordenando moradias alternativas no caso de deslocamentos forçados, embora tenham sido criticados por privar as partes de um remédio judicial efetivo de fato (BANGLADESH, Aino Salish Kendra and others (ASK) vs. Government and Bangladesh and others, 2001)

(iv) emissão de uma série de ordens contínuas e provisórias antes de chegar a uma ordem final (INDIA, People's Union for Civil Liberties vs. Union of India, 2001; INDIA, People's Union for Civil Liberties vs. Union of India, 2004)

(v)O uso cauteloso de medidas liminares pode ser uma forma de evitar a crítica que recebem as ordens judiciais mais sistemáticas de que não oferecem nada a vítimas em curto prazo (ROACH, 2008, p. 46). 
formas alternativas de intervenção menos intensa que almejem a materialização do direito (TUSHNET, 2009, p. 249; 254).

Em síntese, estas três variáveis permitem avaliar a existência de um diálogo institucional: clara afirmação da justiciabilidade do direito em questão, cujo conteúdo inclui algumas tarefas dirigidas ao Poder Público (direitos fortes), certo grau de deferência às diretrizes políticas traçadas pelos órgãos eleitos pelo povo (comandos brandos) e monitoramento de suas decisões por meio de mecanismos participatórios.

O modelo que alie esses três componentes de maneira a materializar o direito social, com os olhos voltados à promoção da equidade, varia conforme o desenho institucional específico de cada nação (DIXON, 2006, p. 40). Como verificado no levantamento feito anteriormente, a maioria das críticas à judicialização parte justamente do pressuposto de que a atuação do Poder Judiciário é necessariamente intensa (strong form). Os juízes emitem ordens que fixam obrigações de prover determinado produto ou procedimento, sem especial deferência às decisões dos demais poderes acerca do conteúdo das políticas públicas, sobretudo no que se refere à padronização dos medicamentos e tratamentos.

No contexto brasileiro, no que pertine aos desafios que devem ser enfrentados pela jurisprudência, há evidências que sugerem que os encargos burocráticos são geralmente muito mais significativos do que os problemas relativos à seleção de prioridades enquanto explicações para as falhas na concretização da dimensão positiva dos direitos sociais (MENDES; BRANCO, 2011, p. 713). Em outras palavras, as inúmeras vinculações a que está sujeito o orçamento, bem como a existência de políticas públicas abrangentes, indicam que a falha se encontra no momento de implementação. Segundo Christian Courtis (2006, p. 175), nesse caso, mesmo a adjudicação individual de um bem deve ser vista como reforço - e não como ofensa - ao princípio da separação dos poderes.

Assim, examinam-se as peculiaridades dos litígios em saúde no Brasil, a fim de averiguar como esses pressupostos teóricos nos auxiliam a avaliar o quadro brasileiro, bem como a enxergar alternativas que conduzam à materialização do direito à proteção da saúde, orientada pela equidade.

\subsection{Efetividade e equidade: desafios e estratégias}

O Modelo Brasileiro de litigância seria caracterizado, em síntese, pela prevalência das demandas individuais acerca de tratamentos curativos - Hoffman e Bentes, $\left(2008^{10}\right)$ apontaram $98 \%$ de demandas individuais - e de alto grau de acolhimento de seus pleitos (FERRAZ, 2010; PEPE et al, 2010).

Ferraz sustenta que a extrema litigância em matéria de saúde nos moldes brasileiros agrava o estado já precário do Sistema de Saúde nacional, elencando duas razões: (i) uma interpretação do direito a saúde que ignore limites

\footnotetext{
${ }^{10}$ Objeto de pesquisa: 7.400 casos apreciados nos Tribunais do Rio Grande do Sul, Rio de Janeiro, Goiás, Bahia e Pernambuco e no STJ e STF entre 1995 e 2004 . Análise textual e quantitativa.
} 
orçamentários só pode ser sustentada em detrimento da universalidade do sistema, isto é, apenas parcela da população tem acesso a recursos ilimitados e (ii) a minoria que tem acesso as cortes não é a que carece dos bens de saúde mais básicos (FERRAZ, 2010, p. 34).

Bruce Porter (2010, p. 9-11) sugeriu que na avaliação da eficácia do mecanismo de aplicação dos direitos sociais, devemos primeiro nos perguntar o que estamos tentando alcançar com reivindicações de direitos sociais e avaliar as opções de execução contra esses os objetivos e propósitos. No caso do direito à proteção da saúde, como já referido, fala-se em um propósito compensatório no sentido de garantir a participação do povo na distribuição pública de bens (SARLET, 2007, p. 299). A igualdade de oportunidades, portanto, é um uma importante via de análise da implementação de direitos sociais.

O compromisso com a equidade está expresso em cada inciso do art. $3^{\circ}$ que elenca os objetivos fundamentais da República Federativa do Brasil: I construir uma sociedade livre, justa e solidária; II - garantir o desenvolvimento nacional; III - erradicar a pobreza e a marginalização e reduzir as desigualdades sociais e regionais; IV - promover o bem de todos, sem preconceitos de origem, raça, sexo, cor, idade e quaisquer outras formas de discriminação. Uma proposta equânime, portanto, parece se voltar à priorização daqueles que mais necessitam, segregados e negligenciados.

Ora, assentado que o parâmetro de aferição do grau de sucesso da atuação judicial seria a promoção do direito à proteção da saúde orientada pela equidade, em um contexto de justiça social, resta definir o conteúdo desse parâmetro aplicado à realidade brasileira.

A primeira distinção que deve ser feita se volta aos conceitos de equidade e igualdade. Como pontuado por Amartya Sen, "a violação da equidade em saúde não pode ser julgada meramente em termos de desigualdade. (...) Particularmente sério enquanto injustiça é a falta de oportunidade para o alcance de bons níveis de saúde", por motivos alheios a sua vontade, como discriminação ou pobreza (FERRAZ, 2010, p. 36). Assim, as desigualdades se convolam em inequidades quando são evitáveis, desnecessárias e injustas (DAHLGREN; WHITEHEAD apud FERRAZ, 2010, p. 37).

$\mathrm{O}$ aumento de litígios pode incorrer em um efeito regressivo na distribuição de bens públicos por meio de dois mecanismos: a desigualdade entre beneficiários e a desigualdade no domínio político (FERRAZ, 2010, p. 37).

$\mathrm{O}$ primeiro mecanismo se refere à situação em que o acesso aos tribunais se torna dispositivo de racionamento. Constata-se que se os benefícios são apenas nominalmente garantidos a todos, aqueles que recorrem ao Judiciário garantem a sua participação, seja por preferência nas filas, seja pela exclusão dos demais. A desigualdade no domínio político ocorre quando o aumento de litígios força a inserção de benefício dirigido a um determinado grupo na agenda política, tornando o Poder Judiciário mais um canal político de captura de interesses (FERRAZ, 2010, p. 38).

A crítica que pode ser feita a essas conclusões de Ferraz se volta à 
constatação de que não se pode atribuir à judicialização, isoladamente, a instalação desses efeitos regressivos. Ela é mais uma variável que pode provocar reações das instituições estatais: em verdade, estas são produtos de variadas e diversas pressões e influências, sobre as quais as Leis, em geral, e as decisões judiciais, em particular, bem como o papel desempenhado pelos movimentos sociais são apenas exemplos (CANE, 2004, p. 34).

Dentro desse contexto, pergunta-se: se alguma influência há no que se refere à distribuição de recursos, como contornar os potenciais efeitos regressivos da judicialização? A solução não parece ser simplesmente o encolhimento da atuação do Poder Judiciário, sob pena de se consolidar um quadro de nivelamento pela ausência de acesso. Muitas ações versam sobre serviços já contemplados pelas políticas de saúde; nesse caso, a exclusão, em primeiro plano, não é causada pelo Judiciário. Assim, como asseverou o Professor Ingo Sarlet (2009, p. 6), "o direito à saúde não é o direito de igual acesso à falta".

Muitos sustentam que os efeitos regressivos da judicialização podem ser contornados pela adoção preferencial de tutelas coletivas (LIMBERGER, p. 4; LOPES, p. 206; BARROSO, 2007; ORDACGY, 2009; MASCARENHAS, 2009; BARCELLOS, 2008) $)^{11}$. Outra hipótese que se menciona seria a ampliação do acesso às Cortes. $\mathrm{O}$ presente artigo pretende demonstrar a eficácia de mecanismos de diálogo para reorientar os resultados da atuação judicial à materialização equânime do direito à proteção da saúde.

No contexto brasileiro, há que se afastar a abordagem simplista que apenas enxerga a possibilidade de comandos judiciais fortes ou defende a nãojusticiabilidade dos direitos sociais com base em objeções extraídas da teoria democrática e da falta de capacidade institucional dos magistrados. Observa-se, em vez disso, que as importantes falhas institucionais na regulação de saúde e os respectivos problemas de gestão, juntamente com deficiências no estabelecimento de prioridades, além de bloqueios políticos, exigem que os tribunais continuem a desempenhar um papel na efetivação do direito à proteção da saúde. Tal papel, no entanto, não pode ser limitado ao estilo tradicional bilateral de litígios e exige novas intervenções corretivas, como as defendidas pelos partidários da abordagem dialógica.

A judicialização do direito à proteção da saúde ganhou tamanha importância teórica e prática que, em 5 de março de 2009, o então Ministro Presidente do STF convocou Audiência Pública, notadamente um mecanismo de diálogo. Após ouvir os depoimentos prestados pelos representantes dos diversos setores envolvidos, entendeu-se ser necessário redimensionar a questão da judicialização do direito à proteção da saúde no Brasil. A ênfase foi na construção

11 A Corte Constitucional colombiana, por exemplo, decidiu agregar um grande número de pedidos individuais (imediatos e específicos) de acesso ao seguro de saúde e tomar uma decisão de caráter estrutural. $\mathrm{O}$ argumento foi que a proteção do acesso aos seguros de saúde, numa base individual, estava distorcendo as prioridades do sistema de saúde porque as pessoas que mais precisavam de acesso ao seguro de saúde não sabiam que poderia ir ao tribunal para obter proteção (Tutela $n$. 760, Rel. Manuel José Cepeda Espinosa, julgado em 31/07/2008; YAMIN; PARRA-VERA, 2009, p. 147-149). 
de um critério ou parâmetro para a decisão em casos nos quais se discute, primordialmente, o problema da interferência do Poder Judiciário na esfera dos outros Poderes (STA 175, Rel. Min. Gilmar Mendes, DJ de 30.04.2010).

Recomendou-se uma maior cautela através da exposição de parâmetros para as decisões, indicando uma maneira de orientar os magistrados a observar o aspecto coletivo do problema, como por exemplo a análise do registro do medicamento, do quadro clínico da paciente, das rotinas e alternativas veiculadas pelos instrumentos de gestão, dentre outros critérios fornecidos pelos gestores públicos. Nesse sentido, pode-se dizer que estimula um abrandamento dos comandos para conferir certa deferência às diretrizes políticas traçadas pelo Poder Público, uma orientação que se harmoniza à proposta de diálogo institucional.

A inserção do auxílio das assessorias técnicas - resultantes de parcerias de todos os setores envolvidos com as patologias do Sistema de Saúde ${ }^{12}$ - capazes de analisar criticamente os instrumentos de gestão e ensejar decisões judiciais mais balizadas, exemplifica uma outra abertura ao diálogo. O Judiciário assume, assim, que as estratégias de racionamento não estão infensas a controle, mas tampouco podem ser desprezadas: são importantes e necessárias, consubstanciando mais uma postura de certo grau de deferência às diretrizes traçadas pelos demais poderes.

A discussão passa a ser em graus de intervenção, em um cuidado com a intensidade de maneira que se alcance o equilíbrio e mesmo conciliação entre efetividade das disposições constitucionais e equidade do sistema. É necessário algum grau de deferência aos contornos das políticas públicas, partindo-se da premissa de que elas são fruto de um processo democrático de decisões que envolvem escolhas alocativas.

Fala-se em algum grau por reconhecer, igualmente, que esse processo não está imune a falhas, a pontos-cegos, a encargos da inércia, tanto no momento de elaboração quanto no de execução. Por outro lado, as diretrizes fornecidas,

12 A Recomendação n. 31 de 30.03.2010 do CNJ veiculou orientações aos Tribunais pra que adotem medidas dirigidas ao aumento da eficiência na solução das demandas envolvendo assistência à saúde. A primeira recomendação, por exemplo, é a de que sejam instituídos núcleos de assistência técnica compostos por médicos e farmacêuticos que auxiliem os magistrados em face de indagações de natureza clínica que sejam relevantes para a decisão (CNJ. Recomendação n. 31 de 30 de março de 2010. Publicado no DJ-e no 61/2010, em 07/04/2010, p. 4-6). Alguns Tribunais já noticiaram a instalação de assessorias técnicas: Mato Grosso do Sul (TJ assina convênio para criação da Câmara Técnica em Saúde. Sítio do TJMS. Notícia de 26/01/2011. Disponível em: http://www.tjms.jus.br/noticias/materia.php?cod=18670. Acesso 10.03. 2011); Rio de Janeiro (TJ do Rio e Secretaria de Saúde do Estado ampliam serviços do Plantão Médico. Sítio do TJRJ. Notícia de 03/09/2009. Disponível em: http://srv85.tj.rj.gov.br/publicador/exibirnoticia.do?acao=exibirnoticia\&ultimasNoticias=16248\&classe Noticia=2\&v=2. Acesso em 10.03.2011.); Piauí (ASSINADO o termo de criação do Grupo Técnico de Apoio nas questões da Saúde. Notícia de 28/02/2011. Disponível: http://www.tjpi.jus.br/site/modules/noticias/Noticia.mtw?id=1969. Sítio do TJPI. Acesso em 10.03.2011); Minas Gerais (SUPORTE técnico a decisões em saúde. Sítio do TJMG. Notícia de 20/07/2010. Disponível em:http://www.tjmg.jus.br/anexos/nt/noticia.jsp?codigoNoticia=20561. Acesso em 10.03.2011). 
sobretudo no que se refere à alocação de recursos, merecem deferência, devido a dois argumentos: um de autoridade e outro epistêmico. A autoridade estaria relacionada ao fato de os gestores serem eleitos para tal tarefa, e a superioridade epistêmica se refere ao acesso privilegiado a recursos técnicos e informações para a tomada de decisões estratégicas que privilegiam a equidade do sistema (YOUNG, 2011, p. 9-11).

É interessante perceber, ainda, que os efeitos indiretos e simbólicos da própria judicialização impulsionaram a inserção de mecanismos de diálogo institucional, ainda que descolados dos processos judiciais. Um exemplo foi a quebra da inércia institucional: vários órgãos estatais têm se movimentado para tentar solucionar o problema (unlocking effect). Quanto a esse impacto, também observa-se um componente de coordenação entre diversos setores do cenário político-jurídico, sobretudo entre as Defensorias Públicas, as Procuradorias Estaduais, as Secretarias de Saúde, Ministério Público e Poder Judiciário ${ }^{13}$.

Pode-se citar, ainda, o compromisso do Ministro da Saúde de atualização e revisão dos Protocolos Clínicos e Diretrizes Terapêutica, a realização de Fóruns em todo o Brasil para debater a questão, a instalação de Núcleos de Assessoria Técnica aos magistrados, bem como de estruturas de monitoramento das demandas judiciais no desiderato de aperfeiçoar o sistema e evitar o recurso ao Poder Judiciário(MENDES; BRANCO, 2011, p. 715) ${ }^{14}$.

Nesse sentido, antes de desabonar a judicialização por afetar a equidade do sistema, que é o problema de pesquisa analisado, é preciso investigar com seriedade as iniciativas que se constituem em desdobramentos do fenômeno. Tais constatações implicam uma releitura otimista do dilema policêntrico, segundo o qual não seriam apropriadas repercussões para além das partes e dos fatos trazidos à cognição do tribunal.

Desta feita, não se pode deixar de criticar assertivas que não atentem para mudanças outras que numa perspectiva mais alargada possam estar conduzindo à promoção do direito à proteção da saúde e ao aperfeiçoamento do sistema. Há que se ressaltar o papel de descortinamento do problema levado a efeito pela atuação judicial: colocou-o em evidência e ensejou a sua inserção no debate político-

${ }^{13}$ Em Ribeirão Preto e Araquara, as ações judiciais passam por um crivo técnico antes de serem julgadas. O juiz encaminha por via eletrônica a uma comissão multidisciplinar ofício instruído de formulário preenchido pela parte autora da ação, solicitando emissão de parecer em determinado prazo (SOUZA;SANTOS;UETA, 2010, p. 171-172).

${ }^{14}$ A Secretaria de Saúde do Estado de São Paulo e a Defensoria Pública, na capital, firmaram uma parceria com a disponibilização de dois funcionários da Secretaria no prédio da Defensoria que permitiu à população receber os medicamentos necessários não localizados nos postos e hospitais de saúde sem precisar entrar com a ação na Justiça. Houve uma redução de cerca de $90 \%$ nas ações judiciais, casos que passaram a ser solucionados extrajudicialmente e de imediato com a concessão do medicamento pela Secretaria. No Rio de Janeiro foi implantada iniciativa semelhante que acarretou a diminuição das ações em 95\% (ORDACGY, 2009).Tal modelo de conciliação extrajudicial também foi implantado em Minas Gerais (PARCERIA entre defensoria pública e secretarias de saúde beneficiará usuários do SUS. Sítio da Defensoria Pública do Estado de minas Gerais. Disponível em: http://www.defensoria.mg.gov.br/index.php/noticias/44-dpmg/1114-parceria-entre-defensoria-publica-esecretarias-de-saude-beneficiara-usuarios-do-sus.html. Acesso em 10.04.2011). 
institucional. Diante de tantos desafios, a solução parece estar se encaminhando para adoção de estratégias inovadoras que envolvem os diversos atores envolvidos nas demandas de saúde, sem implicar um encolhimento severo da atuação judicial.

A postura de considerar uma esperança vazia a caracterização da atuação judicial como um canal para mudança social, embora pertinente, não pode ser extremada. Tampouco se pode depositar todas as expectativas na litigância enquanto estratégia de implementação de direitos sociais. A abordagem dialógica, como se demonstrou, busca justamente uma posição intermediária, concluindo ser imprescindível um compromisso interinstitucional

\section{CONSIDERAÇÕES FINAIS}

A origem do fenômeno da judicialização crescente em direito à proteção da saúde no Brasil tem sido tradicionalmente relacionada à sua inserção no texto constitucional associada à doutrina da efetividade dos direitos sociais, como indicadora do reforço de sua qualificação enquanto direito fundamental, que não pode convolar-se em "promessa constitucional inconseqüente" (RE 271286 AgR / RS, Rel. Min. Celso de Mello. Dj de 24.11.2000).

Essa visão um tanto quanto atrativa acerca da posição das cortes, desde que infensa a qualquer parâmetro, não pode ser aceita acriticamente. Há um viés de mistificação. Recomenda-se cautela, mas não ceticismo. Há espaço para que os tribunais atuem contra as patologias do processo político na elaboração e implementação das estratégias racionalizadoras do sistema.

Pode-se dizer que o Judiciário cumpriu seu papel de rompimento com doutrinas e posturas que não enxergavam na Constituição uma normatividade capaz de incidir diretamente sobre a realidade social. Não obstante, busca-se um modelo institucional que favoreça uma solução estável a longo prazo, com a realização ótima dos recursos e a materialização do direito à proteção da saúde com os olhos voltados à justiça social.

Procurou-se colher modelos teóricos que favorecem o diálogo entre órgãos e instituições acerca da implementação de direitos sociais. Assim, verificou-se, num plano teórico, que através de um constitucionalismo cooperativo pode se reconhecer, ao mesmo tempo, o pleno potencial e os limites institucionais dos três poderes e a urgente necessidade de realizar os compromissos constitucionais.

A análise do contexto brasileiro evidenciou a prevalência de demandas individuais. Foi referida toda a crítica relativa à potencial promoção de inequidade por meio dos comandos judiciais que desconsideram a dimensão global do sistema de saúde, bem como as limitações orçamentárias e financeiras. Por outro lado, ressaltou-se que tais conclusões não cuidam dos efeitos indiretos e simbólicos da judicialização que podem corresponder a mudanças sistêmicas relevantes para a materialização do direito à proteção da saúde.

A ênfase estrita no alegado papel político assumido pelos tribunais 
possivelmente oculta uma realidade implícita e pouco explorada: as decisões não só refletem as mudanças nas sociedades, mas, por vezes, produzem mudanças políticas e sociais. Observaram-se mudanças qualitativas no cenário jurídicopolítico impulsionadas, sobretudo, pela eleição de critérios para atuação judicial resultante da realização da Audiência Pública Saúde e veiculados pela decisão na STA n. 175 (Rel. Min. Gilmar Mendes, DJe de 30.4.2010).

Assim, há evidências de um quadro misto no que se refere ao impacto das decisões judiciais em saúde inseridas no paradigma de Estado Social no Brasil: se por um lado elas forçam um aumento da responsabilidade governamental e abrem caminho para benéficas mudanças sistêmicas, por outro, se desprezados determinados parâmetros, podem exarcerbar as inequidades existentes. Intentouse demonstrar que, nesse contexto, a inserção de mecanismos de diálogo institucional tem a aptidão de reorientar os efeitos da atuação judicial para a concretização equânime do direito à proteção da saúde.

A materialização do direito à proteção da saúde resulta, por certo, não apenas da atuação eficaz do Poder Judiciário, cujo respaldo é absolutamente relevante, mas de um momento de conscientização e compromisso pulverizado com os direitos fundamentais. É nesse sentido que assumem especial relevo as iniciativas de intersetorialidade.

\section{REFERÊNCIAS}

ASSINADO o termo de criação do Grupo Técnico de Apoio nas questões da Saúde. Sítio do TJPI. Notícia de 28/02/2011. Disponível:

http://www.tjpi.jus.br/site/modules/noticias/Noticia.mtw?id=1969.Acesso em 20.03.2011.

BARATA, Luiz Roberto B.; MENDES, José Dínio Vaz M. Uma proposta de política de assistência farmacêutica para o SUS. In: BLIACHERINE, A.C; SANTOS, J.S. (Orgs.). Direito à vida e à saúde: impactos orçamentário e judicial. São Paulo: Atlas, 2010.

BARCELOS, PC. Perfil de demandas judiciais de medicamentos da Secretaria de Estado da Saúde do Espírito Santo: um estudo exploratório [dissertação]. Rio de Janeiro RJ): Instituto de Medicina Social, Universidade do Estado do Rio de Janeiro, 2010.

BARCELLOS, Ana Paula de. Neoconstitucionalismo, direitos fundamentais e controle das políticas públicas. Revista de direito administrativo n. 240, 2005.

. O direito a prestações de saúde: complexidades, mínimo existencial e o valor das abordagens coletiva e abstrata. Revista da Defensoria Pública, Ano 1, n. 1. São Paulo: Escola de Defensoria Pública do Estado de São Paulo, jul./dez. 2008.

BARROSO, Luis Roberto. Da falta efetividade à judicialização excessiva: direito à proteção da saúde, fornecimento gratuito de medicamentos e parâmetros para atuação judicial. Revista Interesse Público, Belo Horizonte, n. 46, p. 34, nov./dez. 2007. 
. Neoconstitucionalismo e Constitucionalização do Direito. (O Triunfo Tardio do Direito Constitucional no Brasil). Revista Eletrônica sobre a Reforma do Estado (RERE), Salvador, Instituto Brasileiro de Direito Público, no. 9, março/abril/maio, 2007.

BAXI, Upendra, "The avatars of Indian judicial activism," In: VERMA, S. K.; KUSUM (eds), Fifty years of the Supreme Court of India: Its grasp and reach . New Delhi: Oxford University Press, 2000.

BOSI FERRAZ, Marcos. Economia da saúde e sua inserção no sistema da saúde. In: BLIACHERINE, A.C; SANTOS, J.S. (Orgs.). Direito à vida e à saúde: impactos orçamentário e judicial. São Paulo: Atlas, 2010.

BRASIL. Constituição (1988). Constituição da República Federativa do Brasil: promulgada em 5 de outubro de 1988. Artigos 196 a 200. Disponível em:<http://www.planalto.gov.br/ccivil_03/Constituicao/Constituiçao.htm>. Acesso em: 22.4.2009.

. Supremo Tribunal Federal. Recurso Extraordinário n. 271286 AgR/RS.

Relator Ministro Celso de Mello. Acórdão publicado no Diário de Justiça Eletrônico de 24.11.2000. Por unanimidade, a Turma negou provimento ao agravo regimental. 2a. Turma, 12.09.2000.

. Supremo Tribunal Federal. Suspensão de Tutela Antecipada n. 175.

Relator Ministro Gilmar Ferreira Mendes. Acórdão publicado no Diário de Justiça Eletrônico de 30.04.2010. O Tribunal, por unanimidade e nos termos do voto do Relator, Ministro Gilmar Mendes (Presidente), negou provimento ao recurso de agravo. Plenário, 17.03.2010.

CANE,Peter 'Understanding Judicial Review and Its Impact'. In HERTOGH, M; HALLIDAY, S. (orgs.).Judicial Review and Bureaucratic Impact: International and Interdisciplinary Perspectives . Cambridge: Cambridge University Press, 2004. (p. 15-43).

CARVALHO NETTO, Menelick de. Requisitos pragmáticos da interpretação jurídica sob o paradigma do Estado Democrático de Direito. In: Revista de Direito Comparado. Belo Horizonte: Curso de Pós-Graduação em Direito da UFMG e Mandamentos. v. 3. mai./1999.

CATTONI DE OLIVEIRA, Marcelo Andrade. Devido Processo Legislativo. Belo Horizonte: Mandamentos, 2000.

CAVALCANTI, Hylda. Demandas de saúde passam de 112 mil em todo o país. Agência CNJ de Notícias. Notícia de 8.11.2010. Disponível em:

https://www.cnj.jus.br/noticias/10118-demandas-de-saude-passam-de-112-mil-emtodo-o-pais. Acesso em 10.03.2011.

CHALMERS, Alan. "Teorias como estruturas: os paradigmas de Kuhn”. In:O que é ciência, afinal? Tradução: Raul Fiker, $1^{\mathrm{a}}$ ed., $3^{\mathrm{a}}$ reimpressão. São Paulo:Brasiliense, 1993. (p. 123-136) 
CHAYES, A. The Role of the Judge in Public Law Litigation. Harvard Law Review, v. 89, 1976 p. 1281-1316.

COLÔMBIA. Corte Constitucional. Sentencia de Tutela n⿳ 760/08. Autor: Luz Mary Osorio Palacio y Otros. Demandado: Colpatria Eps y Otros. Relator Manuel José Cepeda Espinosa, La Sala Segunda de Revisión de la Corte Constitucional, julgado em 31/07/2008. Disponível em: http://corte-constitucional.vlex.com.co/vid/43476921\#ixzz1OyG54PWt.

COURTIS, Christian. Judicial Enforcement of Social Rights: Perspectives from Latin America. In: GARGARELLA, R. DOMINGO, P.; ROUX, T. (Eds.). Courts and Social Transformationin New Democracies: An Institutional Voice for the Poor?. Aldershot/Burlington: Ashgate, 2006.

CONSELHO Nacional de Justiça. Recomendação n. 31 de 30 de março de 2010. Publicado no DJ-e no 61/2010, em 07/04/2010, p. 4-6

CONSELHO Nacional de Secretários de Saúde. Assistência Farmacêutica no SUS / Conselho Nacional de Secretários de Saúde. Coleção Progestores - Para entender a gestão do SUS, 7- Brasília : CONASS, 2007.

DEL NERO, CR.; CLARK, Otávio; VIANNA, Denizar. Medicina baseada em evidências como ferramenta para as decisões judiciais. In: BLIACHERINE, A.C; SANTOS, J.S. (Orgs.). Direito à vida e à saúde: impactos orçamentário e judicial. São Paulo: Atlas, 2010.

DIXON, Rosaline. Creating dialogue about socio-economic rights: strong v. Weakform judicial review revisited. Center For Human Rights And Global Justice Working Paper. Economic, Social And Cultural Rights Series n. 3, 2006.

ELIAS, Paulo Eduardo. Uma visão do SUS. SUS - o que você precisa saber sobre o Sistema único de Saúde. São Paulo: Associação Paulista de Medicina, 2004, v.1.

ELSTER, Jon . Local Justice. Cambridge, Cambridge University Press, 2000.

FERRAZ Octavio. The right to health in the courts of Brazil: Worsening health inequities?. Health and Human Rights: An International Journal, North America, Vol. 11, n. 02, 2010.

. Harming the Poor Through Social Rights Litigation: Lessons from Brazil. In: SEMINÁRIO 2011 TEXAS LAW REVIEW SYMPOSIUM SOBRE CONSTITUCIONALISMO LATINO-AMERICANO. Anais eletrônicos. University of Texas School of Law, Eidman Courtroom, 4 de Março de 2011.

Disponível em: http://www.texaslrev.com/events/symposium. Acesso em 10.03.2011.

. Right to Health Litigation in Brazil, an Overview of the research. In: CONGRESSO "RIGHT TO HEALTH THROUGH LITIGATION? CAN COURT ENFORCED HEALTH RIGHTS IMPROVE HEALTH POLICY?”. Anais eletrônicos. University Torquato di Tella, Buenos Aires, April 2009. Disponível em: http://papers.ssrn.com/sol3/papers.cfm?abstract_id=1426011. Acesso em 10.03.2011. 
. Right to health litigation in Brazil: Why are collective suits so hard to enforce. Disponível em: http://www.escr-net.org/usr_doc/Ferraz__Implementing_the_Right_to_Health_in_Brazil.pdf. Acesso em 14 mar. 2011. Não paginado.

FERRAZ, Octávio Luiz Motta and VIEIRA, Fabiola Sulpino. Direito à proteção da saúde, recursos escassos e equidade: os riscos da interpretação judicial dominante.

Dados Revista de ciencias sociais, vol.52, n.1, 2009, pp. 223-251.

FULLER, L. The Forms and Limits of Adjudication. Harvard Law Review, v. 92, p. 353-409, 1979.

GARAVITO, César R. Beyond the Courtroom: the impact of judicial Activism on Social and Economic Rights in Latin America. In: SEMINÁRIO 2011 TEXAS LAW REVIEW SYMPOSIUM SOBRE CONSTITUCIONALISMO LATINO-

AMERICANO. Anais eletrônicos. University of Texas School of Law, Eidman Courtroom, 4 de Março de 2011. Disponível em:

http://www.texaslrev.com/events/symposium. Acesso em 10.03.2011.

GARGARELLA, R. 2006. Theories of Democracy, the Judiciary and Social Rights. In: __ .; DOMINGO, P.; ROUX, T. (Eds.). Courts and Social

Transformationin New Democracies: An Institutional Voice for the Poor? Aldershot/Burlington: Ashgate, p. 13-34.

HERTOGH, M. HALLIDAY, S.Judicial Review and Bureaucratic Impact: International and Interdisciplinary Perspectives . Cambridge: Cambridge University Press, 2004.

HOFFMAN, F.; BENTES, F. Accountability for Economic and Social Rights in Brazil. In: GAURI, V.; BRINKS, D. (Org). Courting Social Justice: Judicial Enforcement of Social and Economic Rights in the Developing World. Nova Iorque: Cambridge University Press, 2008, p. 100-145

\section{INTERNATIONAL COMISSION OF JURISTS. Courts and the Legal} Enforcement of Economic, Social and Cultural Rights: Comparative experiences of justiciability. ICJ: Geneva, 2008.

LANGFORD, Malcolm. Judicialização dos direitos econômicos, sociais e culturais no âmbito nacional: uma análise socio-jurídica. Sur, Rev. int. direitos humanos, São Paulo, v. 6, n. 11, Dec. 2009 .

LIMBERGER, Temis. O dogma da discricionariedade administrativa: a tensão instaurada entre os poderes judiciário e executivo devido as políticas de saúde no Brasil. Revista de Interesse Público, Belo Horizonte, ano 11, n. 57, set. 2009.

LIMBERGER, Temis. SALDANHA, Jania M. L. O direito a saúde e sua efetividade: o debate democrático perante o Supremo Tribunal Federal. Revista de Interesse Público. Belo Horizonte, ano 12, n. 64, nov. 2010. 
LINS, Liana C. A tutela inibitória coletiva das omissões administrativas: em enfoque processual sobre a justiciabilidade dos direitos fundamentais sociais. Revista Direito do Estado n. 12, Rio de Janeiro: Renovar/Instituto Idéias, out-dez 2008, p. 223-261

LOPES, José Reinaldo de Lima. Brazilian Courts and Social Rights: A Case Study Revisited. In: GARGARELLA, R. DOMINGO, P.; ROUX, T. (Eds.). Courts and Social Transformationin New Democracies: An Institutional Voice for the Poor?. Aldershot/Burlington: Ashgate, 2006.

LOPES, José Reinaldo de Lima. Direitos sociais: teoria e prática. São Paulo: Editora Método, 2006. P. 230-231.

LOTUFO, Paulo Andrade. Coffee, samba, football and... social inequalities: reflections on mortality in São Paulo, Brazil. São Paulo Med. J., vol.119, n.3, 2001.

\section{MASCARENHAS, Rodrigo Tostes de A. Discurso proferido na Audiência}

Pública da Saúde. Supremo Tribunal Federal [online]. 7 maio de 2009. Disponível em:http://www.stf.jus.br/portal/cms/verTexto.asp?servico=processoAudienciaPublica Saude. Acesso em 10.12.2010.

\section{MEDEIROS, M. Princípios de Justiça na Alocação de Recursos em Saúde.}

Brasília: Ipea, 1999. (Texto para discussão n. 687)

MENDES, Gilmar Ferreira. BRANCO, Paulo Gustavo Gonet. Curso de Direito Constitucional. 6 ed. rev. e atual. São Paulo: Saraiva, 2011.

OLIVEIRA, Marina Helena Barros de. Discurso proferido na Audiência Pública da Saúde. Supremo Tribunal Federal [online]. 7 maio de 2009. Disponível em:http://www.stf.jus.br/portal/cms/verTexto.asp?servico=processoAudienciaPublica Saude. Acesso em 10.12.2010.

ORDACGY, André da Silva.Discurso proferido na Audiência Pública da Saúde. Supremo Tribunal Federal [online]. 7 maio de 2009. Disponível em:http://www.stf.jus.br/portal/cms/verTexto.asp?servico=processoAudienciaPublica Saude. Acesso em 10.12.2010.

PARCERIA entre defensoria pública e secretarias de saúde beneficiará usuários do SUS. Sítio da Defensoria Pública do Estado de minas Gerais. Disponível em: http://www.defensoria.mg.gov.br/index.php/noticias/44-dpmg/1114-parceria-entredefensoria-publica-e-secretarias-de-saude-beneficiara-usuarios-do-sus.html. Acesso em 10 abr.2011.

PEPE, Vera Lúcia Edais et al. A judicialização da saúde e os novos desafios da gestão da assistência farmacêutica. Ciênc. saúde coletiva, v.15, n.5, 2010 pp. 2405-2414.

PIOVESAN, Flávia. Justiciabilidade dos direitos sociais e econômicos: desafios e perspectivas.In: Revista da Defensoria Pública, Ano 1, n. 1. São Paulo: Escola Escola de Defensoria Pública do Estado de São Paulo, jul./dez. 2008. 
PORTER, Bruce. In defense of soft remedies (sometimes): enforcing principles remedies to systemic social rights claims in Canada. In: SYMPOSIUM ON ENFOCEMENT OF ECONOMIC, SOCIAL AND CULTURAL RIGHTS JUDGMENTS: TOWARDS A THEORY AND PRACTICE. Anais eletrônicos. Bogotá, Colombia , 6-7 de maio de 2010. Disponível em: http://www.escrnet.org/actions_more/actions_more_show.htm?doc_id=1156638\&parent_id=115663 7. Acesso em 10.03. 2011.

RIO GRANDE DO SUL. Lei 9.908 de 16.6.1993. Dispõe sobre o fornecimento de medicamentos excepcionais para pessoas carentes e dá outras providências.

Disponível em :

http://www.al.rs.gov.br/legis/M010/M0100099.ASP?Hid_Tipo=TEXTO\&Hid_Toda sNormas $=14687 \&$ hTexto=\&Hid_IDNorma=14687. Acesso em 11 de março de 2011.

ROMERO LC. Judicialização das políticas de assistência farmacêutica: o caso do distrito federal. Brasília: Consultoria Legislativa do Senado Federal; 2008 ROSENBERG, Gerald N.The Hollow Hope: Can Courts Bring About Social Change? Chicago: University of Chicago Press, 1991.

SABEL, Charles F.; SIMON, William H. Destabilization Rights: How Public Law Litigation Succeeds. Harvard Law Review N. 1016, 2003-2004

SANTOS, Maria Lourido dos. Políticas públicas (econômicas) e controle. Revista de Informação Legislativa 158:265-278. Brasília: Senado Federal, abr./jun., 2003.

SANTOS, CC, Guimarães LG, Gonçalves SA. Estratégias para reorganização e otimização das atividades destinadas ao fornecimento de medicamentos demanda- dos judicialmente contra a Secretaria de Estado de Saúde do Distrito Federal [monografia de especialização]. Brasília (DF): Faculdade de Ciências da Saúde, Universidade de Brasília; 2006

SARLET, I. W.; FIGUEIREDO; M.F. Reserva do possível, mínimo existencial e direito à proteção da saúde: algumas aproximações. Revista da Defensoria Pública, Ano 1, n. 1. São Paulo: Escola Escola de Defensoria Pública do Estado de São Paulo, jul./dez. 2008.

SARLET, Ingo W. A Eficácia dos direitos fundamentais. $7^{\mathrm{a} e d}$. Rev. Atual. E ampl.Porto Alegre: Livraria do Advogado. 2007, p.407

Algumas considerações em torno do conteúdo, eficácia e efetividade do direito à proteção da saúde na constituição de 1988. Revista Eletrônica sobre a Reforma do Estado (RERE), Salvador, Instituto Brasileiro de Direito Público, no. 11, setembro/outubro/novembro, 2007.

.Discurso proferido na Audiência Pública da Saúde. Supremo Tribunal Federal [online]. 7 maio de 2009. Disponível em:http://www.stf.jus.br/portal/cms/verTexto.asp?servico=processoAudienciaPublica Saude. Acesso em 10.07.2010. 
SARMENTO, Daniel. O neoconstitucionalismo no Brasil: riscos e possibilidades. Biblioteca Digital Revista Brasileira de Estudos Constitucionais - RBEC, Belo Horizonte, ano 3, n. 9, jan./mar. 2009. Disponível em:

$<\mathrm{http}: / /$ www.editoraforum.com.br/bid/bidConteudoShow.Aspx?idConteudo=56993. Acesso em: 1.02.2011.

SOUZA, Hórtis. SANTOS, José S. Dos; UETA; Julieta. A influência da gestão do sistema de saúde na utilização da via judicial para acesso a produtos e serviços. In: BLIACHERINE, A.C; SANTOS, J.S. (Orgs.). Direito à vida e à saúde: impactos orçamentário e judicial. São Paulo: Atlas, 2010.

STRECK, Lenio L. A interpretação do direito e o dilema acerca de como evitar juristocracias: a importância de Peter Häberle para superação dos atributos (Eigenshaften) solipistas do Direito. Observatório da Jurisdição Constitucional, ano $4,2010 / 2011$.

SUNDFELD, Carlos Ari.Fundamentos de Direito Público. $4^{\text {a }}$ edição. Malheiros Editores Ltda: São, Paulo 2007.

SUNKIN, Maurice. Conceptual issues in researching the impact of judicial review on government bureaucracies. in Hertogh,M.; Halliday,S(orgs.). Judicial Review and Bureaucratic Impact: International and Interdisciplinary Perspectives.

Cambridge: Cambridge University Press, 2004. (p. 43-76)

SUPORTE técnico a decisões em saúde. Sítio do TJMG. Notícia de 20/07/2010. Disponível em:http://www.tjmg.jus.br/anexos/nt/noticia.jsp?codigoNoticia=20561. Acesso em 10 mar.2011.

SUS oferece duas novas vacinas para 6 milhões de crianças. Fiocruz Minas Centro de Pesquisas René Rachou. Disponível em: http://www.cpqrr.fiocruz.br/ptbr/noticias-gerais/sus-oferece-duas-novas-vacinas-para-6-milhoes-de-criancas. Acesso em 10.03.2011.

TAVEIRA, Christiano de Oliveira; TRAVASSOS, Marcelo Zenni. O controle das leis orçamentárias à luz dos direitos humanos: reflexões teóricas e análise jurisprudencial aplicadas sobre o direito à proteção da saúde. Biblioteca Digital Fórum de Contratação e Gestão Pública - FCGP, Belo Horizonte, ano 8, n. 92 , ago. 2009. Disponível em: $<\mathrm{http}: / /$ www.editoraforum.com.br/bid/bidConteudoShow.aspx?idConteudo=62158>. Acesso em: 8 nov. 2010.

TJ assina convênio para criação da Câmara Técnica em Saúde. Página eletrônica do Tribunal de Justiça do Mato Grosso. Notícia de 26/01/2011. Disponível em: http://www.tjms.jus.br/noticias/materia.php?cod=18670. Acesso em 10.03.2011.

TJ do Rio e Secretaria de Saúde do Estado ampliam serviços do Plantão Médico. Página Eletrônica da Secretaria de Saúde do Estado do Rio de Janeiro. Notícia de 03/09/2009. Disponível em http://www.saude.rj.gov.br/imprensa-noticias/366- 
sesdec-e-tj-ampliam-convenio-que-permitiu-criacao-de-nucleo-de-assessoria-tecnicano-tribunal. Acesso em 10.03.2011.

TORRES, Ricardo Lobo. A metamorfose dos direitos sociais em mínimo existencial. In: Ingo Wolfgang Sarlet (Org.) Direitos Fundamentais Sociais: Estudos de Direito Constitucional, Internacional e Comparado. Rio de Janeiro: Renovar, 2003.

TORRES, Ricardo Lobo. Curso de direito financeiro e tributário. 13. ed. Rio de Janeiro: Renovar, 2006

TUSHNET, Mark. Weak courts, strong rights: judicial review and social welfare rights in comparative constitutional law. Princeton: Princeton University Press, 2009.

VALE, André R. Aspectos do Neoconstitucionalismo. Revista Brasileira de Direito Constitucional. RBDC n. 09, jan.jun. 2007 P. 67-77.

VASCONCELOS, Wagner e LOPES, Claudia Rabelo Lopes. Quando o remédio pode virar veneno. Radis, comunicação em saúde. N. 43, março de 2066. Rio de Janeiro

VIEIRA, F.S. Ações judiciais e o direito à proteção da saúde: reflexão sobre a observância aos princípios do SUS, Revista de Saúde Pública, 42 (2), 2008.

YAMIN, A.; PARRA-VERA, O. How Do Courts Set Health Policy? The Case of the Colombian Constitutional Court. PLoS Medicine, v. 6, n. 2, 2000.

YOUNG, Katharine. A Typology of Economic and Social Rights Adjudication: Exploring the Catalytic Function of Judicial Review. International Journal of Constitutional Law (ICON), 2011. Disponível em :

http://icon.oxfordjournals.org/content/early/2011/02/10/icon.moq029.full. Acesso em 20.04.2011.

ZUCCHI, Paola. Distorções causadas pelas ações judiciais à política de medicamentos no Brasil. Revista Saúde Pública [online], v. 41, n. 2, p. 214-222, 2007.

Recebido em 08-09-2011

Avaliado em 24-10-2011

Aprovado para publicação em 05-12-2011 